\title{
Socioeconomic variation in injury in children and older people: a population based study
}

\author{
R A Lyons, S J Jones, T Deacon, M Heaven
}

Injury Prevention 2003;9:33-37

\begin{abstract}
Objectives: To compare hospital admission rates for all causes and specific causes of injury in children and the elderly by a measure of economic deprivation.

Study design: All emergency admissions for Welsh residents from 1997-99 were located to one of 865 electoral tracts, which were grouped into fifths using a measure of socioeconomic deprivation. Standardised admission rates for all ages and 0-14, 15-75, and 75+ year groups for each quintile were calculated with $95 \%$ confidence intervals. Results: There were 90935 admissions in a population of 2.84 million yielding a crude admission rate of $1601 / 100000$ /year and a standardised rate of 1493/100 000. The ratio of admissions in deprived and affluent areas varied with category of injury and age group. In general, socioeconomic variations in injury rates were much smaller in older people than in children with the exception of pedestrian related injuries where the rates were similar. The largest variations were for injuries sustained in assaults or self inflicted.

Conclusions: The relationship between socioeconomic position and injury varies by cause and age group. This should be considered when developing area based preventive interventions or monitoring the effectiveness of policies to reduce inequalities in injury occurrence.
\end{abstract}

See end of article for authors' affiliations

Correspondence to: Professor Ronan Lyons, Centre for Postgraduate Studies, Clinical School, University of Wales

Swansea, Singleton Park Swansea SA2 8PP, UK; r.a.lyons@swansea.ac.uk

$\mathrm{T}$ he strong link between injury mortality and socioeconomic status is well documented..$^{1-8}$ However, the relationship between non-fatal injuries and socioeconomic position is less clear cut, with several papers describing a link, ${ }^{9-14}$ while others suggest any such links are not strong..$^{15-17}$ One of the difficulties in studying non-fatal injuries is that use of medical services is often used as a proxy but there is evidence in the UK that less affluent children may be more readily admitted to hospital. This may confound the relationship between deprivation and injury occurrence. ${ }^{18}$ However, in countries without comprehensive health insurance or coverage, the reverse may be true: that is, less affluent children being less likely to be hospitalised. ${ }^{190}$ Moreover, most of the research in this area has focused on children and there is a dearth of information on the relationship between non-fatal injuries and socioeconomic position in other age groups, particularly older people.

The aim of this study was to compare hospital admission rates in small areas across Wales and to relate these rates to deprivation in children and the elderly for the major causes of injury.

\section{METHODS}

Data were drawn from the Patient Episode Database for Wales (PEDW) for 1997-98 and 1998-99. All records with an International Classification of Diseases, 10th revision (ICD-10) S or $\mathrm{T}$ code were included. PEDW is a centralised database of all hospital admissions to Welsh residents and contains details such as address of residence, admission, and discharge dates, ICD-10 and procedure codes. Using the postcode of the home address, people were assigned to electoral tracts ( 844 divisions in Wales, average population 3360). Electoral tracts or divisions were then assigned to five equally sized deprivation groups based on the distribution of the Townsend index of deprivation. $^{21}$

The Townsend index is a composite area based score reflecting unemployment rates, household overcrowding, access to a car, and non-owner occupied housing. Each variable is weighted equally and the index has a mean of zero and a standard deviation of 1 . The most affluent fifth of electoral tracts had Townsend scores of -6.5 to -2.7 and the most deprived had scores from +2.2 to +16.4 . The population of the electoral tract fifths were as follows: 745,$201 ; 605,675 ; 541$, 682; 459, 947; and 482, 635. Analysis of discharges by all causes and by main categories of external causes (ICD-10), was carried out for all lengths of stay, and for all ages, under $15,15-75$, and $75+$ year olds. Analyses are provided for all intents and separately for assault (X60-X84) and self harm (X85-Y09) injuries.

Analyses by cause combine intentional and non-intentional and are grouped into pedestrian (V01-V09) and nonpedestrian road transport injuries (V10-V79), falls (W00W19), burns and scalds (T20-T32), and poisonings (T36-T50). The main objective of the analyses is to compare children with older people, but it was decided to include data on the remaining age group for the sake of completeness. Analysis was limited to emergency admissions only to prevent double counting of people who may have been subsequently admitted for secondary elective procedures.

Previous research in the UK has shown that less affluent children may be more readily admitted to hospital after an injury and that $4+$ day admissions are a better, but not perfect, indicator of severity. ${ }^{18}$ However, analysis by $4+$ day lengths of stay showed similar results to all lengths of stay and have been omitted. Directly standardised rates per 100000 population using the World Health Organisation world standard population were calculated to facilitate international comparisons. ${ }^{22}$

For age subgroups we used the world standard population distribution within each age group to produce rates and 95\% confidence intervals. Standardised hospitalisation ratios and 95\% confidence intervals were also calculated to examine whether the results in each fifth of electoral tracts differed from the Welsh average.

Abbreviations: ICD, International Classification of Diseases, PEDW Patient Episode Database for Wales 


\section{RESULTS}

Over the two year study period, 90935 injury discharges after emergency admission occurred among 2.84 million people. Ninety percent had a valid external cause code assigned; falls accounted for $37.1 \%$, poisonings $22.5 \%$, road transport injuries $7.1 \%$, and burns and scalds $0.5 \%$. Unintentional injuries accounted for $85.7 \%$ and deliberate self harm contributed $9.7 \%$ and assaults $4.6 \%$; $18.3 \%$ of injury admissions were under 15 year olds and a $19.9 \%$ involved $75+$ year olds.

Table 1 shows the number of people, world standardised rate, and 95\% confidence intervals, by age group and cause of injury, for all emergency admissions. For all admissions, and admission related to self harm, assaults, falls, pedestrian injuries, poisoning and burns, there are socioeconomic gradients with higher rates in the more deprived communities for all younger age groups. For older people only pedestrian injuries and assault related injuries show a substantial socioeconomic gradient.

Table 2 shows the standardised hospitalisation ratios and 95\% confidence intervals for each category and group. If the $95 \%$ confidence interval does not include 100 then the group differs from the Welsh average.

\section{DISCUSSION}

This study shows that the relationship between socioeconomic position and hospital admissions for injury is affected by age and by cause of the injury. In general, socioeconomic variations in injury admissions are substantially lower in older people than in childhood. In particular, there is little evidence of a substantial influence of socioeconomic position on the occurrence of all injuries or on most specific causes of injury in older people. Because of the large sample even small differences between groups will be statistically significant. The small difference between affluent and deprived areas for all injuries, injuries due to self harm, poisoning, or falls in the elderly is not of any public health significance and suggests that intervention strategies need to be targeted at the entire community.

\section{Limitations}

The relationship between deprivation status and injury in the elderly could be biased by their movement into group homes outside their original area of residence. We analysed the location of all nursing and residential homes in two typical areas of Wales and found that the distribution was $19.4 \%$ (most affluent), $25 \%, 13.9 \%, 18.1 \%$, and $23.6 \%$ across the fifths of electoral tracts. As only $8.8 \%$ of people aged 75 and over in Wales live in such accommodation, the magnitude of any bias caused by such movement is likely to be small and would not substantially affect our reported results. ${ }^{23}$

Deaths that occur at the place of injury or en route to hospital pose difficulties for all researchers. In Wales such deaths are not included in the hospital utilisation database. We analysed published statistics on deaths (ICD-9 codes) involving Welsh residents in the year 2000 and the number of deaths after hospital admission during the same period, to see what effect this may have on our results. In that year, 20 suicide victims died in hospital compared with a total of 256 recorded on death certificates. If undetermined deaths (ICD-10: Y10-Y34 and ICD-9: E980-989) are also included then the comparison is 21 versus 345. For road transport related injuries (ICD-10: V01-V79, ICD-9: E810-819, E826-829) 28 in-hospital deaths occurred compared with 200 recorded on death certificates. Clearly, most suicide or road transport related deaths occur at the scene or before entering hospital and this analysis can say little about these deaths. Unfortunately, as the death and hospitalisation databases are not linked in Wales we cannot adjust for this factor. However, as there are many more admissions than deaths (ratio for self harm admissions/suicide is 12:1 and for road transport related admissions/deaths it is 13:1) the exclusion of these data could not materially affect the results reported.

Admission rates for pedestrian injuries are substantially higher in more deprived areas for all age groups. This suggests that pedestrian safety initiatives targeted to the most deprived communities will benefit all age groups.

It should be noted our analysis is based on the home address of patients rather than the location of the injury. However, there is evidence that in children pedestrian injuries tend to occur near the home and so the use of the home address as a proxy for location is reasonable in this instance. ${ }^{24}$ The variation in pedestrian injuries between affluent and deprived areas that we found is similar to that reported recently from a region of England using a similar approach. ${ }^{14}$

It is interesting to contrast the distribution of pedestrian and non-pedestrian road traffic crash injuries. There is no relation between deprivation status and the likelihood of hospital admission for injury as a car occupant. However, this analysis does not take into account exposure. People in poorer areas may have less access to cars (and hence be at a lower risk of being in a crash) but may be more likely to be injured in a less safe vehicle. Larger, more expensive cars, have better crash protection features. $^{25}$

The largest difference between affluent and deprived areas is for admissions after assault and self harm. Excess assault related admissions were found for both children and older people, no doubt reflecting the more dangerous external social environment in deprived areas. In contrast, the patterns of self inflicted injuries is different, showing a substantial effect for children from deprived neighbourhoods, but little or no effect in older people from the same areas. This must reflect differences in the internal social environment between age groups in the same areas.

The majority of admissions for self harm were as a result of intentional poisoning $(8295 / 8798,94 \%)$. The rate ratio for such poisonings for all ages was similar to that for intentional poisoning $(2.99 v 2.91)$. However, it is often difficult to assess intentionality in cases of poisoning. A detailed examination of the causes behind the findings is beyond the scope of this paper.

There is also a substantial excess of burn and scald related admissions in the less affluent areas. In case specific analyses the rate ratios for the most deprived communities are highest in children but there is also an excess in other age groups. Sixty two percent of all burn or scald cases involved children compared with 7\% in those over 75 years, indicating that children are a priority for burn prevention. Our results are similar to those reported by Hippisley-Cox et al. ${ }^{14}$

It should also noted that ours is an ecological analysis in which an area based attribute (deprivation) is applied to all individuals in that area. This relationship may be different had individually based socioeconomic measures such as social class or income or educational levels been used. However, the ecologic data should prove useful in choosing interventions and age groups when area based interventions are appropriate. They can also be used to monitor the effectiveness of programmes aimed at reducing inequalities in injury occurrence.

The findings of this study suggest that sweeping generalisations about the relationship between injury occurrence and socioeconomic position are best avoided and that patterns vary by cause of injury and age group affected.

\section{Authors' affiliations}

R A Lyons, Collaboration for Accident Prevention and Injury Control, Department of Epidemiology, Statistics and Public Health, University of Wales College of Medicine, Cardiff and Centre for Postgraduate Studies, Clinical School, University of Wales Swansea, Swansea, Wales, UK S J Jones, T Deacon, M Heaven, Collaboration for Accident Prevention and Injury Control, Department of Epidemiology, Statistics and Public Health, University of Wales College of Medicine, Cardiff 
Table 1 Number of admissions, world standardised admission rates, and $95 \%$ confidence intervals (CI) by age group, deprivation status, and cause

\begin{tabular}{|c|c|c|c|c|c|c|c|c|}
\hline \multirow[b]{2}{*}{ Deprivation fifth/cause } & \multicolumn{2}{|c|}{ All ages } & \multicolumn{2}{|c|}{$0-14$ years } & \multicolumn{2}{|c|}{$15-75$ years } & \multicolumn{2}{|c|}{$75+$ years } \\
\hline & No & Rate $(95 \% \mathrm{Cl})$ & No & Rate $(95 \% \mathrm{Cl})$ & No & Rate $(95 \% \mathrm{Cl})$ & No & Rate $(95 \% \mathrm{Cl})$ \\
\hline \multicolumn{9}{|l|}{ All admissions } \\
\hline Deprived & 29026 & 3840.72 (3808.29 to 3873.15$)$ & 5729 & 3614.55 (3520.95 to 3708.15$)$ & 19123 & $3717.00(3664.31$ to 3769.68$)$ & 4174 & 9684.06 (9390.27 to 9977.85$)$ \\
\hline Less deprived & 20474 & 3250.41 (3217.20 to 3283.61$)$ & 3845 & 3341.40 (3235.78 to 3447.02 ) & 12488 & 2976.51 (2924.31 to 3028.72 ) & 4141 & $9344.73(9060.10$ to 9629.35$)$ \\
\hline Middle & 16304 & 2837.89 (2805.12 to 2870.67 ) & 2802 & 2872.67 (2766.30 to 2979.04 ) & 9818 & 2606.94 (2555.22 to 2658.67 ) & 3684 & 8599.22 (8321.54 to 8876.91 ) \\
\hline Less affluent & 13484 & 2743.67 (2708.77 to 2778.56 ) & 2284 & 2784.35 (2670.16 to 2898.55 ) & 7978 & 2492.15 (2437.46 to 2546.83 ) & 3222 & 9146.83 (8830.99 to 9462.67 ) \\
\hline Affluent & 11647 & 2256.24 (2225.32 to 2287.16 ) & 2015 & 2352.42 (2249.71 to 2455.14 ) & 6792 & 1983.74 (1936.56 to 2030.91 ) & 2840 & 8718.06 (8397.42 to 9038.69$)$ \\
\hline \multicolumn{9}{|c|}{ 1900.74 (11900.00 } \\
\hline Deprived & 3641 & 490.84 (474.90 to 506.79 ) & 64 & 39.36 (29.79 to 48.93 ) & 3538 & 711.31 (687.87 to 734.74$)$ & 38 & 83.62 (57.04 to 110.21 ) \\
\hline Less deprived & 1916 & 322.12 (307.69 to 336.54$)$ & 37 & 28.45 (19.28 to 37.62$)$ & 1849 & 465.25 (444.04 to 486.45$)$ & 30 & 64.86 (41.65 to 88.07 ) \\
\hline Middle & 1469 & 281.75 (267.34 to 296.16$)$ & 27 & 24.10 (15.01 to 33.19 ) & 1428 & 408.07 (386.90 to 429.23 ) & 14 & 31.77 (15.13 to 48.42 ) \\
\hline Less affluent & 1127 & 257.58 (242.54 to 272.62 ) & 20 & 20.64 (11.59 to 29.68$)$ & 1088 & $372.96(350.80$ to 395.12$)$ & 19 & 54.81 (30.17 to 79.46$)$ \\
\hline Affluent & 645 & 134.91 (124.50 to 145.32$)$ & 12 & 11.06 (4.80 to 17.32 ) & 608 & 193.92 (178.51 to 209.34$)$ & 25 & 72.09 (43.83 to 100.35 ) \\
\hline \multicolumn{9}{|l|}{ Assaults } \\
\hline Deprived & 1769 & 246.11 (234.64 to 257.58 ) & 100 & 63.86 (51.34 to 76.38$)$ & 1661 & 336.25 (320.08 to 352.42$)$ & 8 & 19.45 (5.97 to 32.93 ) \\
\hline Less deprived & 962 & 174.04 (163.04 to 185.04 ) & 61 & 53.96 (40.42 to 67.50 ) & 896 & 233.62 (218.33 to 248.92 ) & 5 & 12.16 (1.50 to 22.82$)$ \\
\hline Middle & 657 & 137.34 (126.84 to 147.84$)$ & 47 & 50.00 (35.71 to 64.30 ) & 607 & 180.88 (166.49 to 195.27 ) & 3 & $7.44(-0.98$ to 15.85$)$ \\
\hline Less affluent & 500 & 121.84 (111.16 to 132.52$)$ & 18 & 22.85 (12.29 to 33.41$)$ & 477 & 170.54 (155.23 to 185.84$)$ & 5 & 13.21 (1.63 to 24.79$)$ \\
\hline Affluent & 295 & 69.85 (61.88 to 77.82 ) & 9 & 10.31 (3.57 to 17.05$)$ & 284 & $99.13(87.60$ to 110.66$)$ & 2 & 6.51 (-2.51 to 15.54$)$ \\
\hline \multicolumn{9}{|c|}{ (10.00 } \\
\hline Deprived & 9458 & 1078.84 (1057.09 to 1100.58 ) & 2214 & 1383.95 (1326.30 to 1441.60$)$ & 4158 & 733.58 (711.28 to 755.88$)$ & 3086 & 7223.79 (6968.91 to 7478.66$)$ \\
\hline Less deprived & 7401 & 961.64 (939.73 to 983.55 ) & 1506 & 1289.27 (1224.15 to 1354.38 ) & 2963 & $621.52(599.14$ to 643.90$)$ & 2932 & 6632.88 (6392.79 to 6872.97$)$ \\
\hline Middle & 6361 & 884.18 (862.45 to 905.91$)$ & 1142 & 1154.52 (1087.56 to 1221.48 ) & 2515 & 579.65 (556.99 to 602.30$)$ & 2704 & 6318.58 (6080.42 to 6556.75$)$ \\
\hline Less affluent & 6011 & 974.58 (949.94 to 999.22$)$ & 1052 & 1251.71 (1176.07 to 1327.35 ) & 2373 & 636.89 (611.27 to 662.52$)$ & 2586 & 7365.79 (7081.89 to 7649.69$)$ \\
\hline Affluent & 4536 & 722.79 (701.76 to 743.83$)$ & 840 & 953.85 (889.34 to 1018.35 ) & 1727 & 441.18 (420.37 to 461.99$)$ & 1969 & 6098.50 (5829.13 to 6367.88 ) \\
\hline \multicolumn{9}{|l|}{ Non-pedestrian RTAs } \\
\hline Deprived & 1332 & 195.25 (184.76 to 205.73 ) & 315 & 189.94 (168.96 to 210.91$)$ & 970 & 197.63 (185.19 to 210.07 ) & 47 & 102.70 (73.34 to 132.06$)$ \\
\hline Less deprived & 1113 & 202.85 (190.93 to 214.77 ) & 238 & 191.07 (166.79 to 215.34$)$ & 828 & 208.49 (194.29 to 222.69 ) & 47 & 101.01 (72.13 to 129.89 ) \\
\hline Middle & 1015 & 208.88 (196.03 to 221.73 ) & 201 & 187.58 (161.65 to 213.52$)$ & 772 & 219.35 (203.88 to 234.82 ) & 42 & 94.26 (65.75 to 122.76 ) \\
\hline Less affluent & 949 & 225.41 (211.07 to 239.75$)$ & 187 & 205.40 (175.96 to 234.84$)$ & 692 & 232.73 (215.39 to 250.07 ) & 70 & 187.79 (143.80 to 231.78$)$ \\
\hline Affluent & 859 & 190.72 (177.97 to 203.47$)$ & 147 & 157.30 (131.87 to 182.73) & 671 & 206.07 (190.48 to 221.66 ) & 41 & 115.82 (80.37 to 151.27 ) \\
\hline \multicolumn{9}{|l|}{ Pedestrian RTAs } \\
\hline Deprived & 423 & 63.16 (57.14 to 69.18) & 177 & 108.04 (92.12 to 123.96 ) & 201 & 39.59 (34.12 to 45.06 ) & 45 & 103.21 (73.06 to 133.37 ) \\
\hline Less deprived & 247 & 46.26 (40.49 to 52.03 ) & 90 & 75.26 (59.71 to 90.81$)$ & 130 & 31.25 (25.87 to 36.62$)$ & 27 & 62.32 (38.81 to 85.82 ) \\
\hline Middle & 189 & 39.94 (34.25 to 45.64$)$ & 70 & 68.44 (52.41 to 84.47$)$ & 94 & 25.16 (20.07 to 30.24$)$ & 25 & 59.27 (36.04 to 82.51$)$ \\
\hline Less affluent & 169 & 41.73 (35.44 to 48.02 ) & 56 & 64.55 (47.64 to 81.45$)$ & 92 & 29.74 (23.66 to 35.81$)$ & 21 & 57.49 (32.90 to 82.08 ) \\
\hline Affluent & 121 & $28.27(23.23$ to 33.30$)$ & 41 & 43.88 (30.45 to 57.32 ) & 63 & 19.69 (14.83 to 24.55$)$ & 17 & 51.66 (27.10 to 76.22$)$ \\
\hline \multicolumn{9}{|l|}{ All poisoning } \\
\hline Deprived & 8231 & 1180.10 (1154.61 to 1205.60$)$ & 1012 & 663.63 (622.74 to 704.52$)$ & 7060 & 1433.86 (1400.41 to 1467.31 ) & 159 & 352.54 (297.74 to 407.34$)$ \\
\hline Less deprived & 4581 & 839.11 (814.81 to 863.41$)$ & 615 & 575.20 (529.74 to 620.66$)$ & 3834 & 969.03 (938.36 to 999.70 ) & 132 & $289.74(240.31$ to 339.17$)$ \\
\hline Middle & 3368 & 703.19 (679.45 to 726.94$)$ & 431 & 479.08 (433.85 to 524.31$)$ & 2810 & 811.90 (781.88 to 841.92 ) & 127 & 295.94 (244.47 to 347.42$)$ \\
\hline Less affluent & 2608 & $638.22(613.73$ to 662.71$)$ & 312 & $427.83(380.36$ to 475.31$)$ & 2168 & 737.52 (706.48 to 768.57$)$ & 128 & 358.68 (296.55 to 420.82 ) \\
\hline Affluent & 1689 & 400.39 (381.29 to 419.48$)$ & 253 & 341.34 (299.28 to 383.40$)$ & 1330 & 425.04 (402.20 to 447.88$)$ & 106 & $319.11(258.36$ to 379.86$)$ \\
\hline \multicolumn{9}{|l|}{ All burns } \\
\hline Deprived & 188 & 33.69 (28.87 to 38.51$)$ & 120 & 81.09 (66.58 to 95.60$)$ & 56 & 10.74 (7.93 to 13.55$)$ & 12 & 27.32 (1 1.86 to 42.78$)$ \\
\hline Less deprived & 109 & 27.51 (22.34 to 32.67$)$ & 73 & 71.65 (55.21 to 88.08 ) & 27 & 6.26 (3.90 to 8.63$)$ & 9 & 19.06 (6.61 to 31.51 ) \\
\hline Middle & 83 & 24.53 (19.25 to 29.81$)$ & 54 & 62.62 (45.92 to 79.32$)$ & 25 & 6.43 (3.91 to 8.95$)$ & 4 & 9.24 (0.18 to 18.30$)$ \\
\hline Less affluent & 65 & 21.73 (16.45 to 27.01$)$ & 36 & 51.59 (34.74 to 68.44$)$ & 24 & 7.37 (4.42 to 10.32 ) & 5 & 14.24 (1.76 to 26.73$)$ \\
\hline Affluent & 51 & 15.44 (11.20 to 19.68$)$ & 25 & 34.89 (21.21 to 48.57$)$ & 21 & 5.92 (3.39 to 8.45 ) & 5 & 15.78 (1.95 to 29.61$)$ \\
\hline
\end{tabular}


Table 2 Standardised hospitalisation ratios (SHR) and $95 \%$ confidence intervals (CI) by age group and deprivation status

\begin{tabular}{|c|c|c|c|c|}
\hline & All ages & $0-14$ years & $15-74$ years & $75+$ years \\
\hline Deprivation fifth & SHR $(95 \% \mathrm{CI})$ & SHR $(95 \% \mathrm{CI})$ & $\operatorname{SHR}(95 \% \mathrm{CI})$ & $\operatorname{SHR}(95 \% \mathrm{Cl})$ \\
\hline \multicolumn{5}{|l|}{ All admissions } \\
\hline Deprived & 122.4 (121.04 to 123.86$)$ & 117.0 (114.00 to 120.06$)$ & 128.5 (126.64 to 130.28 ) & 106.4 (103.16 to 109.61$)$ \\
\hline Less deprived & 104.4 (102.94 to 105.80$)$ & 107.9 (104.5 to 111.32$)$ & 103.8 (102.02 to 105.66$)$ & 102.8 (99.692 to 105.96$)$ \\
\hline Middle & $92.6(91.18$ to 94.02$)$ & 92.8 (89.35 to 96.22$)$ & 91.9 (90.064 to 93.699 ) & 94.4 (91.385 to 97.484 ) \\
\hline Less affluent & 91.1 (89.54 to 92.61$)$ & 90.3 (86.62 to 94.03 ) & 88.2 (86.281 to 90.152$)$ & 99.7 (96.228 to 103.11$)$ \\
\hline Affluent & 76.6 (75.23 to 78.01$)$ & 75.5 (72.233 to 78.829$)$ & $71.1 \quad(69.377$ to 72.758$)$ & 95.4 (91.908 to 98.927$)$ \\
\hline \multicolumn{5}{|l|}{ Self harm } \\
\hline Deprived & 154 (149.01 to 159.01$)$ & 149.9 (113.47 to 186.37$)$ & 154.3 (149.24 to 159.41$)$ & 134.8 (91.945 to 177.67$)$ \\
\hline Less deprived & $101.6(97.082$ to 106.18$)$ & 108.5 (73.549 to 143.48$)$ & 101.4 (96.784 to 106.03$)$ & $108(69.371$ to 146.69$)$ \\
\hline Middle & 88.7 (84.132 to 93.201$)$ & $91.6(57.063$ to 126.18$)$ & 89.2 (84.597 to 93.852$)$ & $52.2(24.84$ to 79.492$)$ \\
\hline Less affluent & 80.5 (75.77 to 85.166$)$ & 77.8 (43.713 to 111.93 ) & 80.5 (75.67 to 85.231$)$ & 84.5 (46.507 to 122.5$)$ \\
\hline Affluent & 43.3 (39.913 to 46.589$)$ & $42.3(18.361$ to 66.213$)$ & 42.2 (38.807 to 45.509 ) & 120.7 (73.358 to 167.95$)$ \\
\hline \multicolumn{5}{|l|}{ Assaults } \\
\hline Deprived & 152.7 (145.59 to 159.83$)$ & 144.9 (116.46 to 173.24$)$ & $153.2(145.81$ to 160.55$)$ & 159.1 (48.839 to 269.3 ) \\
\hline Less deprived & $106.9(100.16$ to 113.67$)$ & $121.5(91.035$ to 152.03$)$ & 106.1 (99.153 to 113.05$)$ & 97.6 (12.052 to 183.19$)$ \\
\hline Middle & 83.9 (77.528 to 90.366$)$ & $110.2(78.723$ to 141.76$)$ & $82.6(76.009$ to 89.147$)$ & $60.7(-7.988$ to 129.38$)$ \\
\hline Less affluent & 76.5 (69.77 to 83.177$)$ & $50.6(27.226$ to 73.982$)$ & 77.7 (70.699 to 84.639$)$ & $121.7(15.027$ to 228.4$)$ \\
\hline Affluent & 42.9 (37.967 to 47.748$)$ & $24(8.305$ to 39.609$)$ & 43.9 (38.792 to 49.003$)$ & $52.7(-20.322$ to 125.64$)$ \\
\hline \multicolumn{5}{|c|}{ 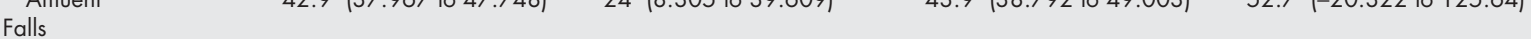 } \\
\hline Deprived & 113.2 (110.9 to 115.46$)$ & 112.3 (107.61 to 116.96$)$ & 118.5 (114.88 to 122.08 ) & 107.3 (103.53 to 111.1$)$ \\
\hline Less deprived & $100.8(98.551$ to 103.15$)$ & 104.4 (99.117 to 109.66$)$ & 101.1 (97.421 to 104.7$)$ & 98.9 (95.337 to 102.5$)$ \\
\hline Middle & 94.1 (91.825 to 96.452$)$ & 93.4 (87.95 to 98.78$)$ & 94.5 (90.778 to 98.162$)$ & $94.2(90.612$ to 97.711$)$ \\
\hline Less affluent & $106(103.31$ to 108.67$)$ & $102.3(96.104$ to 108.47$)$ & $104.7(100.53$ to 108.96$)$ & 108.8 (104.6 to 112.98 ) \\
\hline Affluent & $80.4(78.039$ to 82.718$)$ & 77.2 (71.99 to 82.433$)$ & $73(69.527$ to 76.41$)$ & 90 (85.992 to 93.939$)$ \\
\hline \multicolumn{5}{|c|}{ Non-pedestrian RTAs } \\
\hline Deprived & 93.8 (88.75 to 98.823 ) & $102.4(91.102$ to 113.72$)$ & 91.7 (85.97 to 97.517$)$ & 84.9 (60.617 to 109.15$)$ \\
\hline Less deprived & 98.5 (92.744 to 104.32$)$ & $102.7(89.656$ to 115.75$)$ & $98.2(91.479$ to 104.85$)$ & $86.5(61.74$ to 111.18$)$ \\
\hline Middle & 102.2 (95.897 to 108.47$)$ & 101.8 (87.704 to 115.84 ) & 103.9 (96.547 to 111.2 ) & 79.8 (55.69 to 103.98 ) \\
\hline Less affluent & $113(105.79$ to 120.16$)$ & 110.5 (94.673 to 126.35 ) & $110.4(102.19$ to 118.65$)$ & $158.7(121.56$ to 195.93$)$ \\
\hline Affluent & 97.1 (90.586 to 103.57 ) & 80.8 (67.72 to 93.838$)$ & 101.3 (93.646 to 108.98 ) & 101.1 (70.135 to 132.01 ) \\
\hline \multicolumn{5}{|l|}{ Pedestrian RTAs } \\
\hline Deprived & 137.8 (124.65 to 150.91$)$ & 142 (121.08 to 162.93$)$ & 131.8 (113.59 to 150.03$)$ & 150.6 (106.57 to 194.56$)$ \\
\hline Less deprived & 100.1 (87.641 to 112.62$)$ & $97.2(77.137$ to 117.31$)$ & 104.7 (86.666 to 122.65$)$ & 90.3 (56.244 to 124.37$)$ \\
\hline Middle & 86.7 (74.3 to 99.009 ) & $89(68.125$ to 109.81$)$ & $85(67.837$ to 102.21$)$ & 86.6 (52.646 to 120.53$)$ \\
\hline Less affluent & 91.5 (77.703 to 105.29$)$ & 83.8 (61.857 to 105.76$)$ & 98.1 (78.052 to 118.14$)$ & 87.1 (49.869 to 124.41$)$ \\
\hline Affluent & $62.9(51.662$ to 74.064$)$ & $57.5(39.91$ to 75.121$)$ & 63.7 (47.944 to 79.387$)$ & 76.4 (40.095 to 112.76$)$ \\
\hline \multicolumn{5}{|l|}{ All poisoning } \\
\hline Deprived & 147.6 (144.4 to 150.76$)$ & 127.2 (119.41 to 135.09 ) & $152.2(148.65$ to 155.75$)$ & 110.5 (93.324 to 127.68$)$ \\
\hline Less deprived & 104.3 (101.2 to 107.29$)$ & 109.4 (100.79 to 118.09 ) & $104(100.69$ to 107.28$)$ & 91.4 (75.779 to 106.95$)$ \\
\hline Middle & 87.5 (84.53 to 90.436$)$ & 90.8 (82.248 to 99.397$)$ & $86.8(83.635$ to 90.057$)$ & 90.8 (75.042 to 106.64$)$ \\
\hline Less affluent & 80.6 (77.48 to 83.663$)$ & 80.3 (71.407 to 89.231$)$ & 79.4 (76.017 to 82.698 ) & $109.9(90.82$ to 128.88$)$ \\
\hline Affluent & 49.4 (47.05 to 51.759$)$ & 62.8 (55.078 to 70.559$)$ & $45.7(43.267$ to 48.181$)$ & 98.8 (79.976 to 117.59 ) \\
\hline \multicolumn{5}{|l|}{ All burns } \\
\hline Deprived & 130.8 (112.12 to 149.52$)$ & 124.8 (102.43 to 147.07$)$ & 140.6 (103.80 to 177.48 ) & 155.8 (67.64 to 243.93 ) \\
\hline Less deprived & 102.3 (83.09 to 121.50 ) & 110.3 (85.00 to 135.60 ) & $82.8(51.58$ to 114.06$)$ & 115.9 (40.19 to 191.66$)$ \\
\hline Middle & $90(70.60$ to 109.31$)$ & 97.2 (71.27 to 123.12 ) & 85.6 (52.06 to 119.19 ) & $53.2(1.06$ to 105.39$)$ \\
\hline Less affluent & 85.8 (64.92 to 106.62$)$ & 80.6 (54.28 to 106.96$)$ & 96.5 (57.89 to 135.11$)$ & 79.9 (9.87 to 149.96$)$ \\
\hline Affluent & $65.6(47.63$ to 83.66$)$ & 55 (33.47 to 76.63$)$ & 79.2 (45.33 to 113.08$)$ & $86.8(10.71$ to 162.86$)$ \\
\hline
\end{tabular}

\section{Key points}

- The relationship between socioeconomic position and injury occurrence is not constant and varies by age group and cause of injury.

- Socioeconomic gradients for pedestrian and assault related injuries are common to both children and older people.

- Children, but not older people show a distinct socioeconomic gradient in the incidence of hospitalisations for self harm.

- Falls in older people appear to be little influenced by socioeconomic position.

\section{REFERENCES}

Wise PH, Kotelchuck M, Wilson ML, et al. Racial and socio-economic disparities in childhood mortality. N Engl J Med 1985;313:360-6.

2 Baker SP, Whitfield RA, O'Neill B. Geographic variations in mortality form motor vehicle crashes. N Engl J Med 1987;316:1384-7

3 Mierley MC, Baker SP. Fatal house fires in an urban population. JAMA 1983;249: 1466-8.
4 Nersesian WS, Petit MR, Sharper R, et al. Childhood death and poverty: a study of all childhood deaths in Maine, 1976 to 1980 . Pediatrics 1985;75:41-50

5 Nelson MD. Socio-economic status and childhood mortality in North Carolina. Am J Public Health 1992;82:1131-3.

6 Dougherty G, Pless B, Wilkins R. Social class and the occurrence of traffic injuries and deaths in urban children. Can J Public Health traffic injuries and

7 Roberts I, Power C. Does the decline in child injury mortality vary by social class? A comparison of class specific mortality in 1981 and 1991 BM 1996;313:784-6.

8 Morrison A, Stone DH, Redpath A, et al. Trend analysis of socioeconomic differentials in deaths from injury in childhood in Scotland, 1981-95. BM 1999:318:567-8.

9 Laing GJ, Logan S. Patterns of unintentional injury in childhood and their relation to socio-economic factors. Public Health 1999:113:291-4.

10 Greene D, Raven R, Carvalho G, et al. Epidemiology of facial injury in blunt assault. Determinants of incidence and outcome in 802 patients. Arch Otolaryngol Head Neck Surg 1997;1 23:923-8.

11 Stark AD, Bennet GC, Stone DH, et al. Association between childhood fractures and poverty:population based study. BM 2002;324:457.

12 Laflamme L, Engström K. Socioeconomic differences in Swedish children and adolescents injured in road traffic incidents: cross sectional study. BM 2002:324:396-7.

13 Bagley C. The urban setting of juvenile pedestrian injuries: a study of behavioural ecology and social disadvantage. Accid Anal Prev 1992;24:673-8. 
14 Hippisley-Cox J, Groom L, Kendrick D, et al. Cross sectional survey of socioeconomic variation in severity and mechanism of childhood injuries in Trent 1992-7. BMV 2002;324:1 132-4.

15 Williams JM, Currie CE, Wright $P$, et al. Socio-economic status and adolescent injuries. Soc Sci Med 1996;44:1881-91.

16 Anderson $\mathbf{R}$, Dearwater SR, Olsen T, et al. The role of socio-economic status and injury morbidity risk in adolescents. Arch Pediatr Adolesc Med 1994; 148:245-9.

17 Lyons RA, Delahunty AM, Heaven M, et al. Incidence of childhood fractures in affluent and deprived areas. BM 2000;320:149.

18 Cryer PC Jarvis SN, Edwards $\mathrm{P}$, et al. Why the government was right to change the "Our Healthier Nation" accidental injury target. Public Health 2000;1 14:232-7.

19 Mohan D. Road safety in less-motorised environments: future concerns. Int J Epidemiol 2002;31:527-32.
20 Nantaly VM, Reich MR. The neglected epidemic: road traffic injuries in developing countries. BM 2002;324:1 139-41. 21 Townsend P, Phillimore P, Beattie A. Health and deprivation: inequality

22 Waterhouse J, Correa P, Muir C, et al. Cancer incidence in five continents. Volume III. Lyon: IARC, 1976: 456.

23 Johansen A, Lyons RA, Jones S, et al. Fracture incidence among elderly people in institutional care: linking injury surveillance with a postcode-based register of residential and nursing homes, International Journal for Consumer and Product Safety 1999;6:215-21.

24 Agran PF, Winn DG, Anderson CL. Differences in child pedestrian injury events by location. Pediatrics 1994;93:285-8.

25 Kallan $M$, Elliott $M$, Durbin D. Variation in risk of injury to children by passenger car classification [abstract]. 6th World Conference on Injury Prevention and Control. Montreal: Les presses de L'University de Montreal, 2002: 289-90. 